\title{
Prólogo
}

\author{
Manuel Pantigoso Pecero
}

\section{AULA PALMA EN HOMENAJE AL DOCTOR ESTUARDO NÚÑEZ}

Cuando estaba próximo a cumplir 105 años de edad, este 29 de agosto último falleció Estuardo Núñez, uno de los prominentes estudiosos de la literatura del país. Su deceso no solo remeció los cimientos del Instituto Ricardo Palma -del que fuera Presidente desde su fundación- sino también las bases de la cultura nacional donde era considerado Patriarca y clásico de nuestras letras. Esta edición número 12 de Aula Palma está dedicada a él, a su vida ejemplar y a su obra perdurable que siempre nos ha de impulsar para seguir sin desmayo con el trabajo intelectual en el que estamos comprometidos: el estudio de la vida y obra del Patrono de nuestra Casa de Estudios sobre el cual el doctor Núñez sentó cátedra permanente.

La obra de este ilustre humanista comprende dos áreas de estudio: la literatura peruana y la literatura comparada. En la primera destacan sus textos sobre José María Eguren, Pablo de Olavide, Juan de Arona, la poesía peruana y la literatura en general. Respecto a Eguren hay que destacar que su enfoque lo coloca como el fundador en el Perú de la crítica estilística. Sobre 
Olavide, este fue revalorizado como novelista y autor teatral gracias a la búsqueda diligente de nuestro gran investigador que ubicó, en bibliotecas norteamericanas y europeas, novelas que hasta entonces eran inhallables. Por otro lado, en el campo de la Literatura Comparada han de sobresalir los trabajos referidos a los "contactos" entre escritores peruanos y la literatura alemana, inglesa, norteamericana, italiana, francesa y brasileña; también, sus estudios sobre "viajeros", tanto de los extranjeros por el Perú -sobresaliendo la figura universal de Von Humboldt- como de los peruanos fuera del país.

La presente edición contiene veintidós trabajos referidos a lo que hemos llamado "Re-visión de las Tradiciones"; quince pertenecen a Miembros de Número del Instituto, todos ellos reconocidas personalidades del acontecer cultural del país: César Coloma Porcari, Wilfredo Kapsoli Escudero, Jesús Cabel Moscoso, Alberto Varillas Montenegro, Iván Rodríguez Chávez, Roberto Reyes Tarazona, Oswaldo Holguín Callo, Eduardo Huárag Álvarez, José Luis Ayala, Ismael Pinto Vargas, Luis Enrique Tord, Pedro Díaz Ortiz, Dora Bazán Montenegro, Lorenzo Huertas Vallejos y Miguel Ángel Rodríguez Rea.

Nos complace dar la bienvenida al doctor Harry Belevan-McBride quien en su calidad de Miembro de Número ingresante participa con un análisis erudito referido a las interpretaciones de Raúl Porras Barrenechea y Sebastián Salazar Bondy sobre Lima. Por su parte, el eminente peruanista Roland Forgues -Miembro Correspondiente de nuestro Instituto- por un lado, ofrece su homenaje a Estuardo Núñez, y por otro escudriña las delicadas texturas verbales de la tradición para extraer "las claves ocultas del pensamiento de Palma", todo expresado con la hondura que 
proviene de su alto magisterio y de su acostumbrada pasión por el Perú. También en este número contamos con un grupo de invitados nacionales procedentes de Piura y Lima: Juan Carlos Adriazola, Carlos Alberto Pérez Garay, Sandro Chiri y Félix Terrones. Como invitada internacional la doctora Mariagloria Cornejo Cousin cimenta la amistad binacional entre Perú y Ecuador. Ella interviene con un lúcido ensayo que traza las vidas paralelas de Ricardo Palma y Justino Cornejo, prototipos de hombres progresistas y liberales arraigados en el cultivo de la tradición y de la lengua de sus respectivos países.

De manera general, el conjunto de ensayos efectúa diferentes calas con variados enfoques sobre la obra de Palma: medicina, religión, historia, política, educación, sociología, costumbres, etc. Y al lado de todo ello, en el centro mismo de la obra, la ironía y el humor para sustentar un espacio y un tiempo en donde funciona la trama social y un estilo absolutamente personal.

Dentro de la línea de homenajes a Estuardo Núñez, Jesús Cabel nos ofrece un ensayo donde pasa revista a los notables estudios realizados por el maestro sobre la obra del autor de las Tradiciones.

3.

Aula Palma lleva, al lado de ella, un anexo nuestro dedicado íntegramente a la vida y a la obra del fundador de nuestro Instituto. Lo hemos titulado Estuardo Núñez: continuidad esencial en el tiempo. Aquí recogemos sus múltiples aportes, especialmente en el campo de la investigación literaria y de la pionera literatura comparada y de viajeros. En todo ello Núñez fue el primero en marcar distancia con esa crítica historicista 
e impresionista para enrumbarse, más bien, por los predios de la estilística, tal como se comprueba en su texto sobre Eguren que ha servido para que se le reconozca como el Fundador de la Crítica Contemporánea en el Perú. Nuestro estudio incluye, por primera vez, un aspecto que no se había tomado en cuenta: el iniciático fervor creativo que tomó cuerpo a través de sus breves relatos escritos con la impronta vanguardista. Estas narraciones -verdaderos pilares que sostendrían su temperamento sensible y reflexivo- sindican a Núñez como un autor adelantado de esa fase vanguardista correspondiente a las primeras décadas del siglo pasado. Además, destacamos otros aspectos: el enfoque crítico de la literatura que el autor realiza a través de un libro clave como fue Panorama actual de la poesía peruana, donde delimita las nuevas orientaciones estéticas y el valioso curso que siguió nuestra poesía sobre todo a partir del expresionismo vallejiano.

4.

Este 9 de octubre el rector de la Universidad, doctor Iván Rodríguez Chávez nos encomendó la Presidencia del Instituto Ricardo Palma, lo cual nos enaltece y compromete para seguir el ejemplo de quien fuera nuestro querido maestro desde las aulas sanmarquinas. El doctor Estuardo Núñez seguirá siendo un ejemplo de sabiduría y de amor por el Perú. 